\title{
Introdução aos bancos de dados biológicos
}

6 By Editor-in-chief

23 de junho de 2021

\section{Introdução aos bancos de dados biológicos}

Leandro Libório (D), Victor Hugo Resende (D)

Revisão: Pedro Martins (D), Diego Mariano (iD

BIOINFO - Revista Brasileira de Bioinformática. Edição \#01. Julho, 2021.

DOI: 10.51780/978-6-599-275326-16

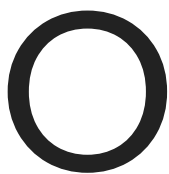

conhecimento biológico é armazenado através de bancos de dados. O fundamento mais importante para a bioinformática aplicada é a coleta de dados de sequência e suas informações biológicas associadas [6]. O armazenamento de dados torna-

se necessário diante ao aumento de volume gerado nos últimos anos e da necessidade de tratamento de informações através de buscas, processamentos e análises de resultados. Portanto, os bancos de dados biológicos utilizam aplicações e sistemas gerenciadores de bancos de dados para manter acessíveis e funcionais as informações de sequências e anotações genômicas, dados de complexos proteicos e suas interações, mapas metabólicos, catálogo de espécies ou recursos naturais, dentre outros exemplos.

Os bancos de dados biológicos têm grande utilidade para a comunidade científica. Existem diversas aplicações e recursos que funcionam como fontes de pesquisa e armazenamento. Espera-se encontrar uma série de benefícios diante ao uso destas aplicações tais como: a informação da localização de um gene, perspectivas de evolução de organismos, dados de expressão genética e características fenotípicas, avaliação do uso de fármacos, interações moleculares e funcionais de proteínas, etc. Há uma lista considerável de possibilidades e desafios no tratamento de dados biológicos. Nos próximos tópicos serão abordados maiores detalhes referentes à classificação destes bancos de dados, de sua estrutura, funcionamento e exemplos de utilização.

\section{Introdução}

Embora o conceito de banco de dados esteja intrinsicamente ligado à Ciência da Computação, boa parte das atividades do nosso dia a dia envolvem organização e armazenamento de informações com um objetivo específico. Neste capítulo, iremos discutir alguns conceitos gerais de banco de dados e sua importância no contexto da bioinformática. 


\section{O que é um banco de dados?}

Um banco de dados é uma coleção de dados relacionados que possuem um significado implícito. Desta maneira, os dados devem ser coerentes e populados nos registros com o intuito de atender alguma finalidade específica ligada a algum aspecto do mundo real. Múltiplos usuários finais realizam transações que devem ser atualizadas e refletidas no banco de dados [1]. Por exemplo: um site de vendas de produtos esportivos disponibiliza diversos itens em sua home page. O acesso ao site é realizado por inúmeros clientes que podem realizar suas compras, e consequentemente atualizam as informações do banco de dados deste vendedor. A manutenibilidade de estoque e oferta destes produtos é automatizada através de operações computacionais por um grupo de programas escritos para esta tarefa.

\section{Sistema de Gerenciamento de Banco de Dados (SGBD)}

O Sistema de Gerenciamento de Banco de Dados (SGBD), do inglês Data Base Management System (DBMS) é um conjunto de programas que gerenciam a estrutura do banco de dados e controlam o acesso aos dados armazenados. O SGBD provê entre os usuários e o banco de dados controle de armazenamento, operações de acesso, compartilhamento, segurança e organização. Existem diversos softwares gerenciadores de bancos de dados como Oracle, SQL Server, PostgreSQL, MySQL, Sybase, DB2, entre outros. Do ponto de vista do gerenciamento real, o SGBD é apenas um dos componentes do Sistema de Banco de Dados (SBD), que por sua vez é composto de cinco partes principais: hardware, software, pessoas, procedimentos e dados [2]. 


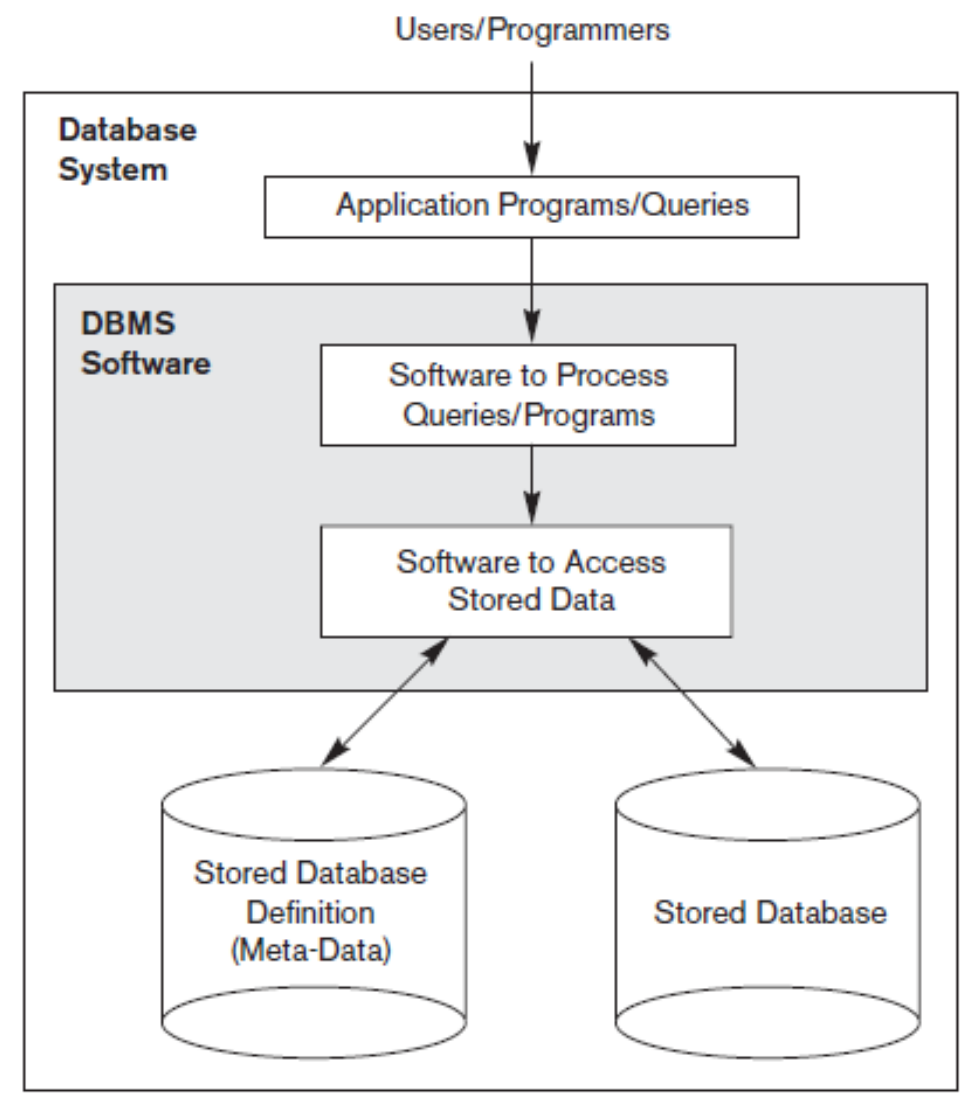

Figura 1: Ambiente simplificado do SBD - Sistema de Banco de Dados. Fonte: Elmasri \& Navathe, 2017 [1].

Tipos de SGBDs ou Modelo de Dados 
- Hierárquico - consiste em registros armazenados em estruturas de dados em árvore com dois componentes principais: tipo de registro e ligação. Estes registros são conectados através de ponteiros de forma que cada registro contém um único valor e cada ligação está relacionada exatamente a dois registros nesta estrutura que se assemelha a uma árvore genealógica com subordinações do tipo pai-filho. O acesso a qualquer registro é feito a partir do registro raiz. Exemplos de bancos de dados com modelo hierárquico: IMS, Adabas.

- Em Rede - baseado no modelo hierárquico adiciona uma extensão das limitações do tipo anterior. Este modelo permite uma estrutura mais completa, organizada em uma rede interligada de registros. O acesso do registro pode ser feito direto ao nó ao invés da necessidade de caminhar a partir da raiz.

- Relacional - proposto em 1970 por Edgar Frank Codd, este modelo é o mais utilizado atualmente e apresenta conceitos de lógica e teoria de conjuntos. Os bancos de dados relacionais possibilitam o tratamento e organização dos dados a partir de relações (tabelas) e das restrições definidas nestes relacionamentos. As consultas sobre as tabelas são baseadas na álgebra relacional através da linguagem SQL (Structured Query Language), conforme veremos com mais detalhes na seção 2.4 deste capítulo. Cada tabela deste modelo é composta por linhas (tuplas) e colunas (atributos). Os principais SGBDs da atualidade utilizam este modelo, por exemplo, Oracle, SQL Server, MySQL, PostgreSQL, etc.

- Orientado a Objetos - cada informação é armazenada na forma de objetos através do paradigma de representação dos dados a partir de abstrações do mundo real. Esse modelo permite maior flexibilidade do que o modelo relacional diante de dimensionamento de dados complexos e na integração com linguagens de programação orientadas a objetos como Python, $\mathrm{C}++$ e Java, por exemplo.
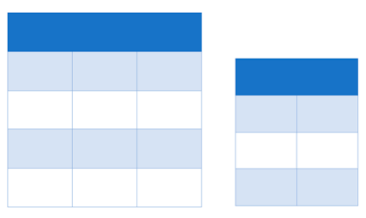

RELACIONAL

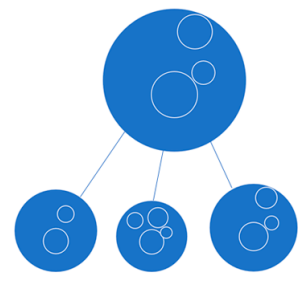

ORIENTADO A OBJETOS

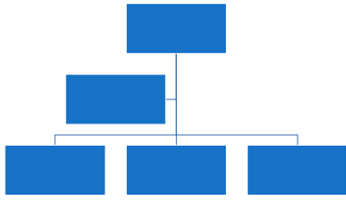

HIERÁRQUICO

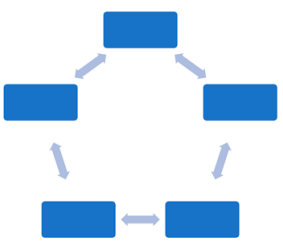

EM REDE

Figura 2: Comparativo entre as representações dos modelos de dados. Fonte: próprio autor.

\section{O que é SQL?}


SQL - Structured Query Language (Linguagem de Consulta Estruturada), é uma linguagem declarativa e não procedural implementada na IBM Research como a interface para um Sistema de Banco de Dados relacional experimental chamado SYSTEM R. É a linguagem padrão dos SGBDs relacionais comerciais atualmente. Sua padronização é realizada pela American National Standards Institute (ANSI). SQL é uma linguagem abrangente que possui instruções para definições de dados (DDL - Data Definition Language) - criação de esquemas e tabelas; e instruções para manipulação de dados (DML - Data Manipulation Language) - inserção, deleção e atualização de registros [1].

\section{- Comando DDL:}

\section{CREATE TABLE clientes (}

cliente_id number(10) NOT NULL,

nome_cliente varchar2(50) NOT NULL, cidade varchar2(50)

);

O exemplo do comando acima, na linguagem Oracle PL/SQL, representa a criação de uma tabela clientes que possui três colunas: cliente_id,

nome_cliente e cidade. Os atributos "number" e "varchar" referem-se aos tipos de dados, valores númericos com até 10 caracteres e valores alfanuméricos com até 50 caracteres, respectivamente. Já a expressão "NOT NULL" indica quais as colunas não podem conter valores nulos - cliente_id e nome_cliente.

\section{- Comando DML:}

\section{mysql > select $*$ from result_blast limit 10 ;}

O exemplo do comando acima, seleciona todas as colunas $(*)$ da tabela result_blast e limita o resultado aos 10 primeiros registros encontrados (cláusula limit 10). Exemplo adaptado de http://biodados.icb.ufmg.br/cromatina/bacharelado/Manual_aula_MySQL.pd f.

\section{Bancos de dados biológicos}

\section{Classificação dos bancos de dados biológicos}

Os bancos de dados biológicos são desenvolvidos para diversos propósitos, abrangem vários tipos de dados com cobertura heterogênea e são curados em diferentes níveis e com métodos diferentes, de modo que existem vários critérios aplicáveis à classificação dos bancos de dados biológicos, como observamos abaixo: 
- Escopo da cobertura de dados: abrangentes ou especializados

- Nível de curadoria: primários ou secundários

- Método de biocuração: curadoria por especialistas ou pela comunidade científica

- Tipo de dados gerenciados: DNA, RNA, proteína, expressão, vias metabólicas, doenças, entre outros. [4]

\section{Alguns exemplos de bancos de dados biológicos}

São exemplos de bancos de dados biológicos [3]:

- Bancos de dados de sequências e estruturas: contém dados de sequências de nucleotídeos, aminoácidos, e de estruturas de proteínas. Exemplos: GenBank; DDBJ (DNA Data Bank of Japan); PDB (Protein Data Bank).

- Bancos de dados de genomas: embora as sequências de genomas constituam entradas nos arquivos-padrão de sequência de ácidos nucleicos, muitas espécies têm bancos de dados especiais que juntam a sequência do genoma e sua anotação com outros dados relacionados às espécies. O Genome é o banco de dados do NCBI que armazena estruturas completas.

- Bancos de dados de padrões de expressão e de proteômica: armazenam as medições dos níveis de mRNA, geralmente por meio das ESTs (Express Sequence Tag ou Etiquetas de Sequências Expressas - sequências terminais curtas de cDNA sintetizadas a partir de mRNA) descrevendo padrões de transcrição de genes. Bancos de dados de proteômica armazenam medidas realizadas com proteínas, descrevendo padrões de tradução de genes.

- Bancos de dados de vias metabólicas: contém vias metabólicas de uma variedade de espécies com integração das informações bioquímicas. Um dos mais importantes e completo banco de dados é o KEGG (Kyoto Encyclopedia of Genes and Genomes).

- Bancos de dados de referências da literatura científica: abrange as informações de citações, resumos e artigos relacionados às pesquisas biológicas. Por exemplo, o PubMed, plataforma popular de pesquisa mantida pelo NCBI.

\section{Outros bancos de dados biológicos}

- NAR - a revista internacional Nucleic Acids Research publica anualmente uma lista extensa de bancos de dados de biologia molecular desde o ano de 1996.

- Bancos de dados NCBI - todos os bancos de dados moleculares mantidos pelo NCBI. Esses bancos de dados estão divididos em 6 grupos principais: nucleotídeo, proteína, estrutura, taxonomia, genoma e expressão.

- Banco de dados EBI - o portal principal de todos os bancos de dados do EBI dividido em vários grupos, como literatura, microarranjo, nucleotídeo, proteína, estrutura, caminho e ontologia [9].

- Protein Data Bank - principal repositório mundial de estruturas de proteínas, DNA e RNA. 


\section{Formatos de arquivos de dados comuns em Bioinformática}

- Formato FASTA: um arquivo no formato FASTA começa com uma linha de descrição seguida por linhas de dados da sequência. A linha de descrição é diferenciada dos dados da sequência por um símbolo maior que (">") no início. É recomendável que todas as linhas de texto tenham menos de 80 caracteres. Uma sequência de exemplo no formato FASTA é:

$>$ P01013 GENE X PROTEIN (OVALBUMIN-RELATED)

QIKDLLVSSSTDLDTTLVLVNAIYFKGMWKTAFNAEDTREMPFHVTKQESKPVQ MMCMNNSFNVATLPAEKMKILELPFASGDLSMLVLLPDEVSDLERIEKTINFEK LTEWTNPNTMEKRRVKVYLPQMKIEEKYNLTSVLMALGMTDLFIPSANLTGISS AESLKISQAVHGAFMELSEDGIEMAGSTGVIEDIKHSPESEQFRADHPFLFLIK HNPTNTIVYFGRYWP

- Formato EMBL: armazena a sequência e sua anotação juntas. O início da seção de anotação é marcado por uma linha que começa com a palavra "ID". A seção de início da sequência é marcada por uma linha que começa com a palavra "SQ". A linha "//" (terminador) também não contém dados ou comentários e designa o final de uma entrada. O arquivo EMBL pode terminar com a extensão .embl ou .txt.

- PDBx/mmclF: é o formato padrão de arquivos do wwPDB (World Wide Protein Data Bank). Armazenam informações de estruturas de biomoléculas.

- GFF: O formato GFF (General Feature Format) é um tipo de arquivo delimitado por tabulação que descreve genes e outras características de sequência de DNA, RNA e proteínas.

- GTF: General Transfer Format - idêntico à versão GFF2.

- SAM: Sequence Alingment Map - armazenam sequências biológicas alinhadas a uma sequência de referência. O formato SAM consiste em uma seção de cabeçalho e uma seção de alinhamento. As linhas na seção de cabeçalho começam com o caractere '@' e as linhas na seção de alinhamento não. Todas as linhas são delimitadas por TAB. [13]

- PIR: uma sequência no formato PIR consiste em: uma linha começando com um sinal " $>$ " (maior que), seguida por um código de duas letras que descreve o tipo de sequência ( $\mathrm{Pl}, \mathrm{Fl}, \mathrm{DL}, \mathrm{DC}, \mathrm{RL}, \mathrm{RC}$ ou XX), seguido por um ponto e vírgula, seguido pelo código de identificação de sequência (o código de identificação do banco de dados). Uma linha contendo uma descrição textual da sequência. Uma ou mais linhas contendo a própria sequência. O final da sequência é marcado com um caractere "*" (asterisco). O formato PIR também é conhecido como formato NBRF [14]. Exemplo de Formato PIR:

$>$ P1; CRAB_ANAPL

ALPHA CRYSTALLIN B CHAIN (ALPHA(B)-CRYSTALLIN)

MDITIHNPLI RRPLFSWLAP SRIFDQIFGE HLQESELLPA SPSLSPFLMR

SPIFRMPSWL ETGLSEMRLE KDKFSVNLDV KHFSPEELKV KVLGDMVEIH

GKHEERQDEH GFIAREFNRK YRIPADVDPL TITSSLSLDG VLTVSAPRKQ SDVPERSIPI TREEKPAIAG AQRK*

Tutorial de exemplo de busca no GenBank 
Agora, para ilustrar o uso de banco de dados biológicos vamos apresentar um breve tutorial de acesso ao banco de dados GenBank. Inicialmente, faça acesso à página inicial de pesquisa: https://www.ncbi.nlm.nih.gov/genbank/.

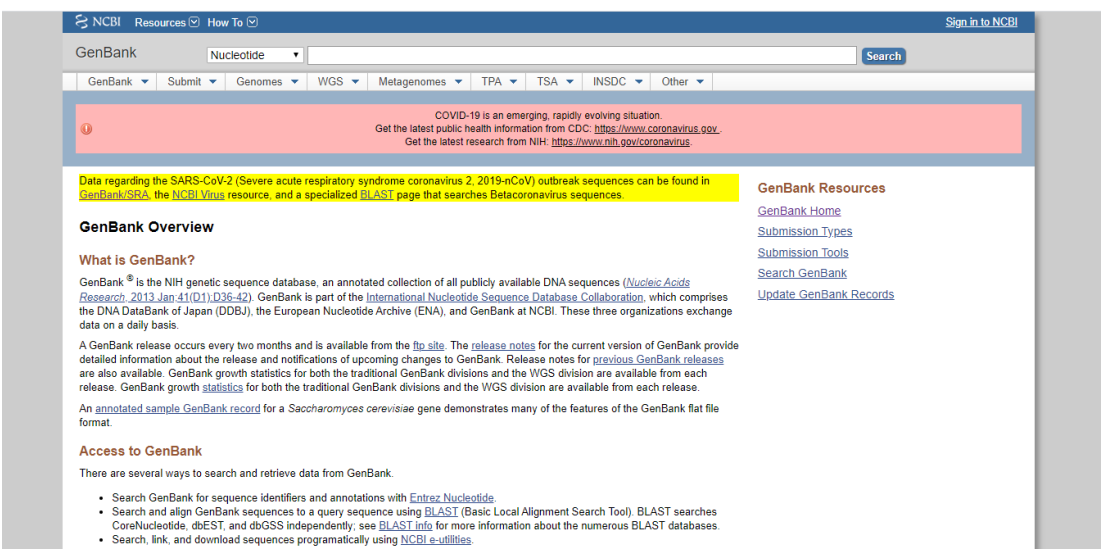

Figura 3: Página inicial do GenBank. Fonte: próprio autor.

Existem várias maneiras de pesquisar e recuperar dados do GenBank. Neste exemplo, iremos buscar as informações de sequências para a proteína P53 em Homo Sapiens.

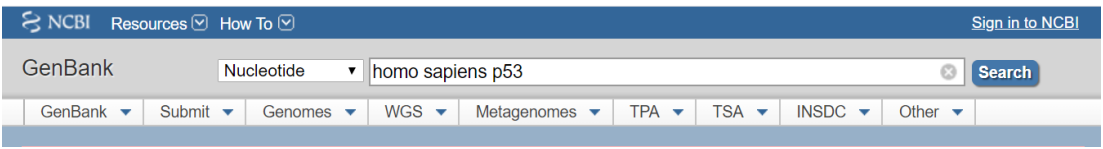

Figura 4: Campo de busca no GenBank. Fonte: próprio autor.

Abaixo estão os resultados da pesquisa. A lista ao lado direito "Results by taxon" mostra o número de resultados retornados por espécie. A busca também pode ser realizada informando os identificadores Accession e GI number. Nesta consulta, o resultado recuperado foi de 22783 registros.

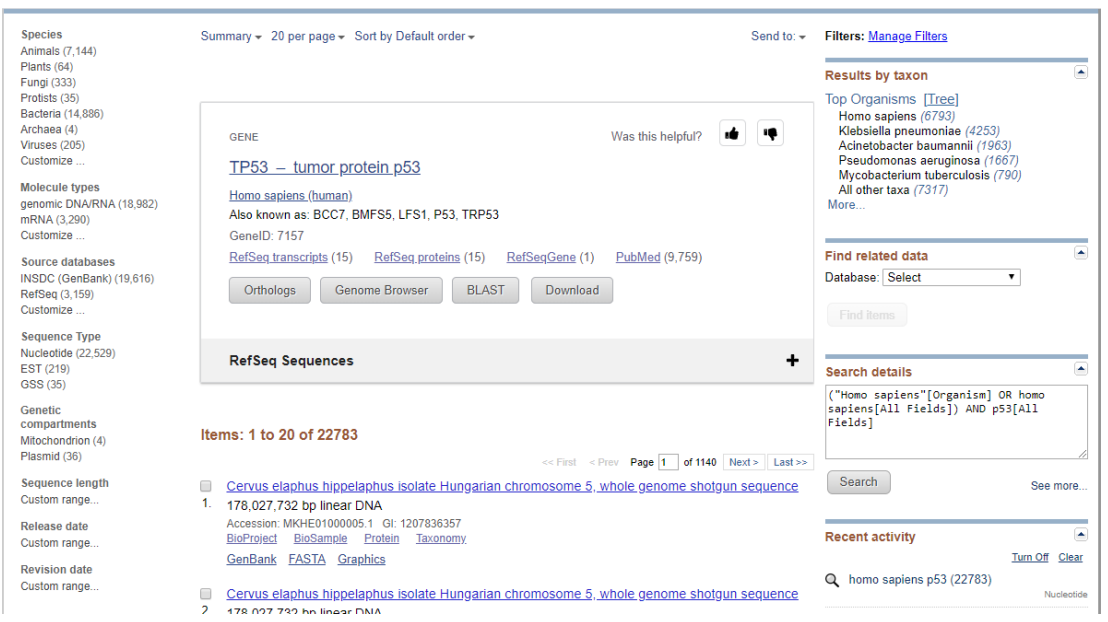

Figura 5: Resultados da consulta realizada. Fonte: próprio autor.

Também podemos analisar os registros recuperados detalhando-os no formato do GenBank, FASTA ou Graphics. 


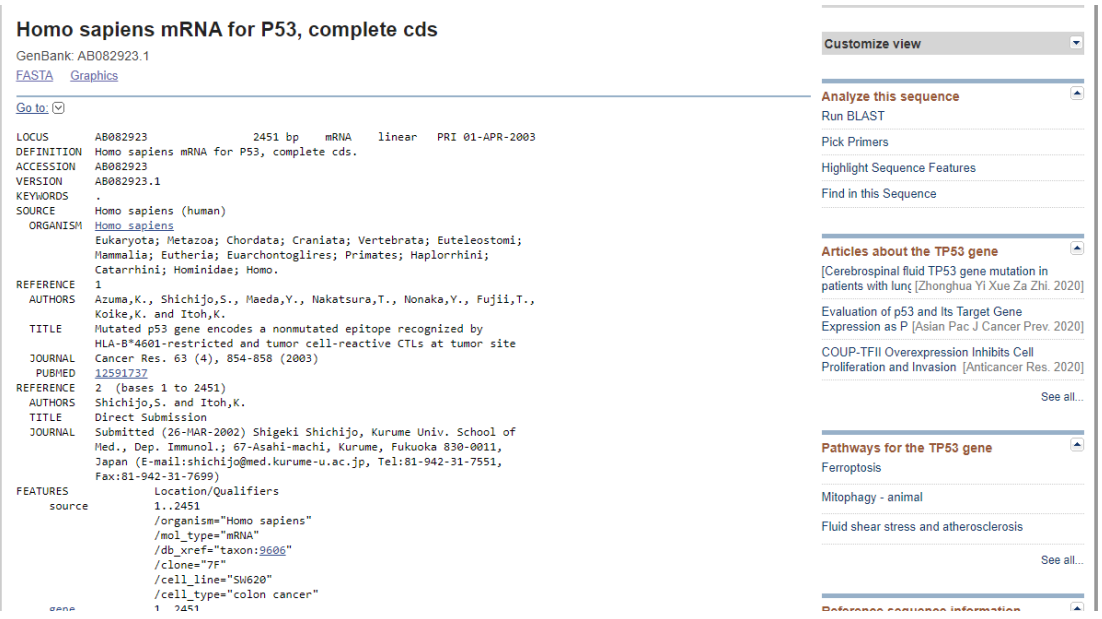

Figura 6: Exemplo de um resultado detalhado - formato de arquivo do GenBank. Temos a descrição, informações das publicações de artigos relacionados, a sequência de nucleotídeos, regiões codificadores de proteínas - CDS (Coding Sequence), etc. Fonte: próprio autor.

É possível realizar o download do arquivo conforme o formato desejado selecionando a opção "Send to", marcando o botão de opção "Choose Destination: File" e em seguida basta clicar em "Create File".

(A)

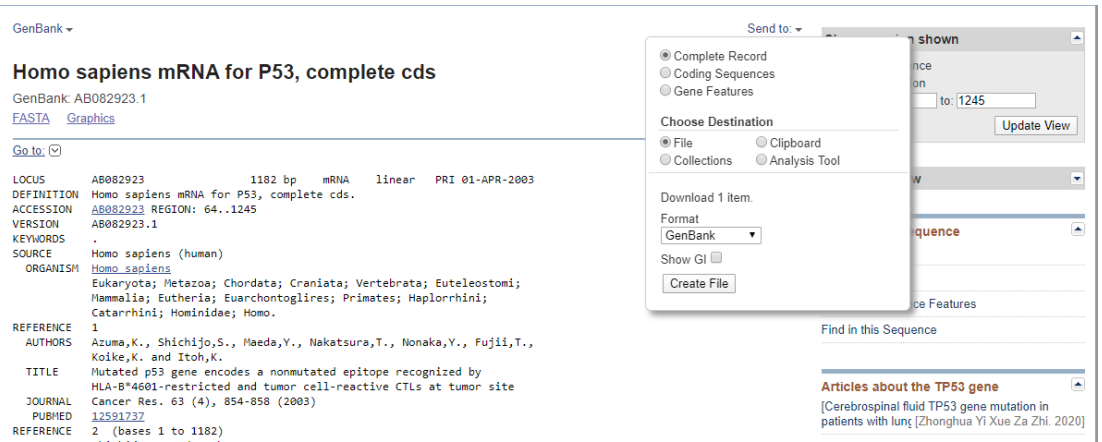

(B)
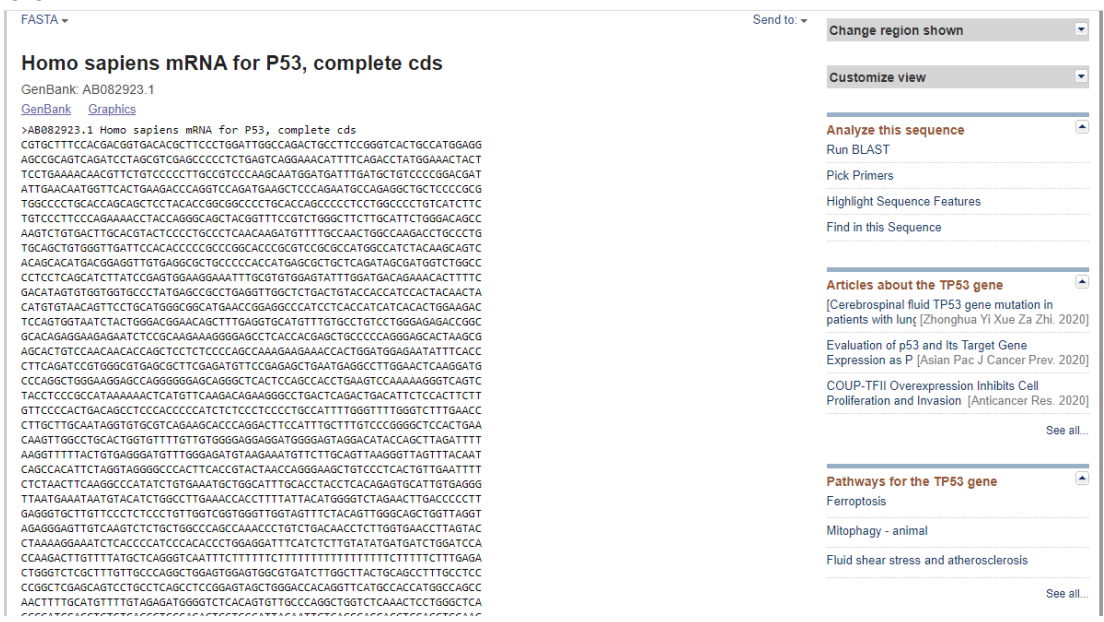

(c) 


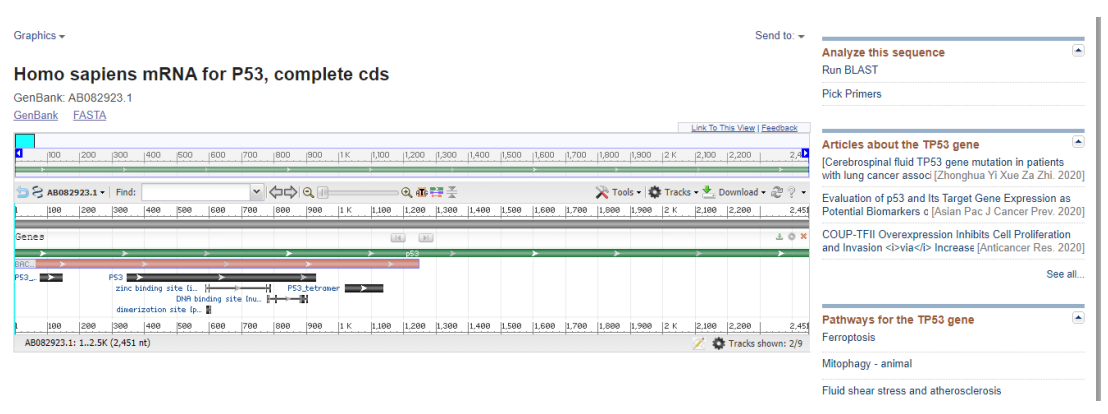

Figura 7: (A) Download do arquivo no formato GenBank. (B) Seleção da visualização do registro localizado no formato FASTA. (C) Visualização da sequência - Graphics. Fonte: próprio autor.

\section{Um pouco mais sobre o PDB}

O PDB "Protein Data Bank" é um banco de dados de estruturas obtidas através de experimentos de difração de raios- $X$ e de nêutrons em cristais e de Ressonância Magnética Nuclear (RMN) de milhares de proteínas [7], tornando-se o maior repositório mundial de informações sobre a estrutura 3D de grandes moléculas biológicas, incluindo os ácido nucleicos. Esse banco apresentava em 20 de abril de 2020 o total de 162.816 arquivos com estruturas de macromoléculas.

Um arquivo de estrutura ou arquivos PDB são representados em um formato específico e padronizado, chamado formato PDB. Esses arquivos são utilizados em programas de modelagem e visualização molecular. Um arquivo PDB pode ser dividido em duas partes principais, a primeira contém informações e detalhes sobre a estrutura e a segunda contém as coordenadas dos átomos. Na primeira seção, informações tais como o método utilizado para resolver a estrutura da proteína, o nome dos autores que resolveram a estrutura, nome da macromolécula e a lista de cadeias disponíveis na estrutura, informações sobre as estruturas secundárias, entre tantas outras informações estão disponíveis. A segunda seção contém informações relativas às coordenadas dos átomos da proteína e dos ligantes (registros chamados de ATOM e HETATM), e informações sobre ligações covalentes e conexões entre átomos (registros chamados de CONECT). A partir destas coordenadas, é possível calcular os tipos atômicos e interações envolvidas entre proteínas e seus ligantes [8].

\section{Referências do capítulo}

[1] ELMASRI, Ramez; NAVATHE, Sham. Fundamentals of database systems. Pearson, 2017.

[2] ROB, Peter; CORONEL, Carlos. Sistemas de banco de dados: Projeto, implementação e gerenciamento. Cengage Learning, 2014. 
[3] LESK, Arthur M. Introdução à Bioinformática. 2.ed. Artmed, 2008.

[4] Zou, Dong et al. "Biological databases for human research." Genomics, proteomics \& bioinformatics vol. 13,1 (2015): 55-63. doi:10.1016/j.gpb.2015.01.006

[5] HARISHA, Sharma. Fundamentals of Bioinformatics. IK International Pvt Ltd, 2010.

[6] SELZER, Paul M.; MARHÖFER, Richard J.; ROHWER, Andreas. Applied bioinformatics. An introduction-Springer, Verlag, Berlin, Heidelberg,

Germany, v. 260, 2008.

[7] https://www.rcsb.org/

[8] https://www.wwpdb.org/documentation/file-format

[9] JIANG, Rui; ZHANG, Xuegong; ZHANG, Michael Q. Basics of Bioinformatics. Springer-Verlag Berlin An, 2016.

[10] https://blast.ncbi.nlm.nih.gov/Blast.cgi?

CMD $=$ Web\&PAGE_TYPE $=$ BlastDocs\&DOC_TYPE $=$ BlastHelp

[11] http://scikit-bio.org/docs/0.5.2/generated/skbio.io.format.embl.html

[12] https://www.ensembl.org/info/website/upload/gff.html

[13] Li, Heng et al. "The Sequence Alignment/Map format and SAMtools." Bioinformatics (Oxford, England) vol. 25,16 (2009): 2078-9.

doi:10.1093/bioinformatics/btp352

[14] http://www.bioinformatics.nl/tools/crab_pir.html

[15] https://br.ccm.net/contents/66-o-que-e-o-sistema-de-gerenciamentode-bancos-de-dados 